\title{
Hypnotic potency differs between desflurane and sevoflurane
}

\author{
Hyun-Kyu Yoon ${ }^{1} \cdot$ Ho-Jin Lee ${ }^{1}$. Won Ho Kim ${ }^{1} \mathbb{C}$
}

Received: 8 July 2019 / Accepted: 31 July 2019 / Published online: 14 August 2019

(c) Japanese Society of Anesthesiologists 2019

Keywords Desflurane $\cdot$ Sevoflurane $\cdot$ Minimum alveolar concentration

To the Editor:

With interest, we read the study by Kanazawa et al. [1]. They compared electroencephalographic finding between 1 MAC of desflurane and sevoflurane in three different age groups. Both bispectral index (BIS) and 95\% spectral edge frequency were significantly lower in desflurane than sevoflurane group, suggesting that the potency of desflurane on the brain is greater than that of sevoflurane at 1 MAC. They conducted study under no surgical stimulation. Recent two trials provided further information under uniform stimulation $[2,3]$. One study compared BIS and surgical pleth index (SPI) between desflurane and sevoflurane under a uniform tetanic stimulation by nerve stimulator [3] and found that both indexes are significantly lower in desflurane group, suggesting that the cerebral effect of volatile agents may differ at 1 MAC. Another study compared the remifentanil requirement to maintain an equal SPI under the same surgical stimulation of dissection of the gall bladder between desflurane and sevoflurane [2]. The remifentanil requirement was significantly lower in desflurane group. All three studies reported consistent results that the potency of desflurane is greater than sevoflurane. Further studies are warranted to evaluate the mechanism.

\section{Compliance with ethical standards}

Conflict of interest No competing interest declared.

\section{References}

1. Kanazawa S, Oda Y, Maeda C, Okutani R. Electroencephalographic effect of age-adjusted 1 MAC desflurane and sevoflurane in young, middle-aged, and elderly patients. J Anesth. 2017;31:744-50.

2. Ryu KH, Kim JA, Ko DC, Lee SH, Choi WJ. Desflurane reduces intraoperative remifentanil requirements more than sevoflurane: comparison using surgical pleth index-guided analgesia. $\mathrm{Br} \mathbf{J}$ Anaesth. 2018;121:1115-22.

3. Ryu KH, Song K, Lim TY, Choi WJ, Kim YH, Kim HS. Does equi-minimum alveolar concentration value ensure equivalent analgesic or hypnotic potency? A comparison between desflurane and sevoflurane. Anesthesiology. 2018;128:1092-8.

Publisher's Note Springer Nature remains neutral with regard to jurisdictional claims in published maps and institutional affiliations.

This comment refers to the article available online at https://doi. org/10.1007/s00540-017-2391-6.

Won Ho Kim

wonhokim.ane@gmail.com

1 Department of Anesthesiology and Pain Medicine, Seoul National University Hospital, Seoul National University College of Medicine, 101, Daehak-ro, Jongno-gu, Seoul 03080, South Korea 